\title{
The Role of a Combination of Autogenous Fresh Bone Marrow and Omental Free Graft in the Cervical Esophageal Wound Healing in Dogs
}

\author{
${ }^{1}$ Omid Azari, ${ }^{1}$ Mohammad Mahdi Molaei, \\ ${ }^{2}$ Reza Kheirandish and ${ }^{1}$ Sara Hamzeh Aliabad \\ ${ }^{1}$ Department of Clinical Sciences, \\ ${ }^{2}$ Department of Pathobiology, \\ Faculty of Veterinary Medicine, Shahid Bahonar University of Kerman, \\ Kerman, Iran
}

\begin{abstract}
Problem statement: Esophageal surgery is associated with greater wound healing problems than surgery on other portion of the alimentary tract. Omentum and fresh bone marrow are rich source of angiogenic factors that promote the growth of blood vessels into wound tissue. The aim of this study was evaluation of the effects of a combination of autogenous fresh bone marrow and omental free graft in esophageal wound healing. Approach: This study was carried out on 8 male adult dogs, assigned into two equal treatment and control groups. All dogs underwent cervical esophagotomy and laparotomy operations, also bone marrow aspiratin, simultaneously. A $3 \mathrm{~cm}$ linear full thickness incision was made on the cervical esophagus and then sutured. In treatment group, A small piece of omentum was obtained from abdominal cavity and secured on esophageal suture line and then $1 \mathrm{~mL}$ of fresh bone marrow was injected into the omental graft and wound edge. In the control group, the suture line was left without any treatment and the harvested omentum and aspirated bone marrow were disposed. During this study, the dogs were examined clinically and they were euthanized 14 days after operation. The surgical site of esophagus was assessed macroscopically and then histopathologic samples were taken from the repaired tissue of esophageal wall. The samples were stained by hematoxylin-eosin and masson-trichorome. Results: The clinical evaluation of present study revealed that all dogs were healthy with no major postoperative complications. There was no significant difference based on macroscopic examination in surgical site of esophagus between the two groups. The microscopic study revealed that inflammatory cells, angiogenesis and granulation tissue formation in wound bed of the treatment group were significantly more than the control group. Conclusion: According to the results of this study, application of a combination of autogenously fresh bone marrow and free omental graft can improve wound healing process in esophageal incision wounds.
\end{abstract}

Key words: Bone marrow, autogenous, omental graft, esophagus

\section{INTRODUCTION}

Alimentary tract adhesion due to the surgical interference and foreign bodies is a major complication, especially in animal practice (Ismail et al., 2007). The esophagus is regarded among surgeons as an infamous organ of the human body and even today it is a great challenge to perform certain types of esophageal operations (Pap-Szekeres et al., 2005). Surgical repair of the esophagus requires meticulous surgical technique because it is more prone to postoperative dehiscence and leakage than other portion of the alimentary tract. Several characteristics of the esophagus make it a less than ideal surgical tissue: it lacks a serosal cover, which may limit leakage by exuding fibrin; it is in constant motion as the result of swallowing and the movement of the diaphragm and adjacent organs; it tolerates longitudinal stretching and tension poorly and it lacks an omentum to help localize and seal a leak (Schunk, 1990). One of the most important features of the anatomy of the esophagus from a surgical aspect is the segmental blood supply of the organ (Pap-Szekeres et al., 2005). During the operative preparation, small supply vessels are injured and the operation is therefore carried out on an organ with a poor blood supply. The postoperative complication rate in esophagus is high (Pap-Szekeres et al., 2005) and cervical esophagus is more prone to the postoperative complication in comparison with the abdominal and

Corresponding Author: Omid Azari, Department of Clinical Sciences, Faculty of Veterinary Medicine,

Shahid Bahonar University of Kerman, Kerman, Iran 
thoracic esophagus, because the cervical part has no serosa or plural mesothelium (Kyles, 2003).

Augmentation of esophagotomy site with omentum, pericardium, local muscle flap, stomatch, or intestine can aid healing by supporting sealing and revascularizing the surgical site (Kyles, 2003; Slatter, 2002). In ideal wound treatment but healing alone is not enough. Restoration of function of the part healed is the ultimate objective (Sharifi et al., 2006a).

It has long been recognized that the greater omentum has great ability in revascularization of tissue and promote angiogenic activity in adjacent structures to which it is applied. Indeed the angiogenuc materials obtained from the omentum is abundant in supply (Saifzade et al., 2007). Because of this unique ability of omentum, it has been used as a pedicle flap in many frequent surgeries such as tracheal autograft (Nakanishi et al., 1994) and ischemic limb (Bhargava et al., 1997). Furthermore omental pedicle flap has been recommended for supporting of esophageal wounds. Omentum is exceptional for esophageal wound patching and closing small defects because it is vascular and available; esophageal stricture formation may also be minimized with omental patching (Slatter, 2002).

In the previous studies, transposition of free omental graft has been used in revascularization procedure involving the chronically injured spinal cord (Zhang et al., 1989), head and neck deformities (Losken et al., 2002) and bone fractures (Oloumi et al., 2006). Bone marrow seems a logical candidate for tereatment of chronic wounds as it contains inflammatory cell progenitors, mesenchymal stem cells andmultipotent stem cells. Infalmmatory cells have long been known to participate in wound healing andhematopoetic hormones such as granulocytemonocyte colony-stimulating factors have been reported to accelerate wound healing (Badiavas and Falanga, 2003). The plasma of bone marrow includes various growth factors and cytokines that are benefit for wound healing process (Moon et al., 2008). Some experimental and clinical studies have confirmed the therapeutic effects of bone marrow on wound healing in various organs (Oloumi et al., 2008; Ichioka et al., 2005; Badiavas and Falanga, 2003; Karaoglu et al., 2009). According to the author's knowledge there is no documented data about the effect of combination of autogenous fresh bone marrow and free omental graft on esophageal wound healing process.

In this study, we have evaluated the role of fresh autogenous bone marrow and free greater omental graft in the healing of experimental cervical esophageal incision, base on clinical, macroscopic andmicroscopic examinations.

\section{MATERIALS AND METHODS}

In this study, eight male adult mixed breed dogs, 23 years old and weighting between 20 and $25 \mathrm{~kg}$, were used. They were determined to be healthy on the basis of physical (body temperature, respiratory rate and heart rate) and hematological examination (CBC, WBC, $\mathrm{PCV}, \mathrm{Hb}$, platelet counts and total protein). The dogs were randomly designed to either an experimental or a control group; 4 dogs in each group. All ethical considerations using animals were considered and the experimental protocol was approved by the Ethics Committee of KUMS.

The animals were premedicated with $0 / 05 \mathrm{mg} \mathrm{kg}^{-1}$ acepromazine (KELA Laboratory, Belgium) intramusculary. Anesthesia was induced intravenously with $10 \mathrm{mg} \mathrm{kg}^{-1}$ thiopental sodium (Thiopental, Caspian, Iran) and maintained with halothane $2 \%$ (Halothane BP, Nicholas, India). After induction of anesthesia, surgical preparation was carried out in the ventral part of abdomen and neck, also proximal part of left humerous in standard method.

In this study, all dogs underwent esophagotomy and laparotomy operation; also bone marrow aspiration. To operate cervical esophagotomy, an incision was made on the midline skin on the ventral surface of the neck, beginning at the larynx and extending caudally to the manuberium. After separation and retraction of local muscles, the trachea was retracted to the right and cervical esophagus was exposed. After this, a stab incision was made into the lumen of esophagus and a 3 $\mathrm{cm}$ linear incision was extended longitudinally. Then surgical site was rinsed by normal saline and esophagotomy incision was closed using 3-0 nylon (Tebkeihan, Iran) with simple interrupted pattern, in both groups.

To carry out laparotomy, the abdominal cavity was approached through a $12-15 \mathrm{~cm}$ ventral midline incision midway between the umbilicus and pelvic inlet. A $3 \times 2$ $\mathrm{cm}^{2}$ piece of the omentum was isolated by two ligatures and cut free from the remaining parts and placed over the esophagotomy incision of treatment group and secured in place with the tacks of sutures. Then $1 \mathrm{~mL}$ of fresh bone marrow was aspirated from proximal part of left humerous by bone marrow aspiration needle and immediately injected into the part of the omental graft that covered esophagus incision, at 3 different points using a syringe with gauge 20 needle. In control group, esophagotomy suture line was left without graft and bone marrow and the isolated omentum and aspirated bone marrow were disposed. Finally, all surgical sites closed routinely. 
Table 1: Criteria for histological scores

\begin{tabular}{|c|c|c|c|c|c|}
\hline Score & Re-epithlialization & Cell infiltration & Granulation tissue & Angiogenesis & Collagen deposition \\
\hline $1-3$ & $\begin{array}{l}\text { Minimal } \\
\text { re-epithelialization }\end{array}$ & $\begin{array}{l}\text { Wound covered with thin } \\
\text { to moderate cell layer }\end{array}$ & $\begin{array}{l}\text { Granulation tissue } \\
\text { around wound edge only }\end{array}$ & $\begin{array}{l}500>\text { capillary } \\
\text { bud } \mathrm{mm}^{-2}\end{array}$ & Low density \\
\hline $4-7$ & $\begin{array}{l}\text { Moderate } \\
\text { re-epithelialization }\end{array}$ & $\begin{array}{l}\text { Wound covered with } \\
\text { thick cell layer }\end{array}$ & $\begin{array}{l}\text { Granulation tissue around } \\
\text { wound edge and in } 30-50 \% \\
\text { of wound bed }\end{array}$ & $\begin{array}{l}500-1000 \text { capillary } \\
\text { bud } \mathrm{mm}^{-2}\end{array}$ & Moderate density \\
\hline $8-10$ & $\begin{array}{l}\text { Complete } \\
\text { re-epithelialization }\end{array}$ & $\begin{array}{l}\text { Wound covered with very } \\
\text { thick and densely } \\
\text { populated cell layer }\end{array}$ & $\begin{array}{l}\text { Granulation tissue around } \\
\text { wound edge and in }>50 \% \\
\text { of wound bed }\end{array}$ & $\begin{array}{l}1000<\text { capillary } \\
\text { bud } \mathrm{mm}^{-2}\end{array}$ & High density \\
\hline
\end{tabular}

Postoperative management included: withheld of oral intake was for 24 hours, intravenous fluids therapy for 2 days, antibiotic (Cefazoline, $20 \mathrm{mg} \mathrm{kg}^{-1}$, IV, tid for 5 days) and anti-inflammatory (Dexamethasone, 0.5 $\mathrm{mg} \mathrm{kg}{ }^{-1}$, IM, single dose) administration in the all dogs.

During this study, the dogs were inspected clinically and then, they were euthanized 14 days after surgery by intravenous injection of sodium thiopental solution. All the soft tissues around the esophagus were retracted and surgical site were studied grossly. A $2 \mathrm{~cm}$ full thickness samples were taken from repair site of esophagus and fixed in 10\% phosphate-buffered formaline. The samples were embedded in paraffin wax afterwards. Five-micrometer serial section of the samples were cut and stained with hematoxylin-eosin andmasson-trichorome andthen examined in a blinded fashion under light microscope. Each slide was given a histological score ranging from 1-10 according to the following parameters: re-epithelialization, wound bed cellularity, angiogenesis, granulation tissue formation and collagen deposition. The amount of collagen deposition was evaluated by masson-trichorome staining andthe other parameters were examined in hematoxylin-eosin stained sections. Angiogenesis was assessed morphometrically by examining three fields per section under $\times 400$ magnifications and presented in number per $\mathrm{mm}^{2}$.

The criteria used for histological scores of wound are summarized in Table 1. The recorded scores of two groups for each parameter were analyzed by using the nonparametric mann-whitney test. A value of $\mathrm{p} \leq 0.05$ was considered as significant.

\section{RESULTS}

All dogs were depressed and lost their appetite for 48 hours post surgery and regained their appetite after that. They were fed with liquid food and gruel in first 7 days after surgery and then gradually returned to their normal diet until the end of the study. All animals remained healthy throughout the study.

The clinical evaluation showed that there is no major postoperative complication such as dysphasia, regurgitation and vomiting in all examined dogs during this study.

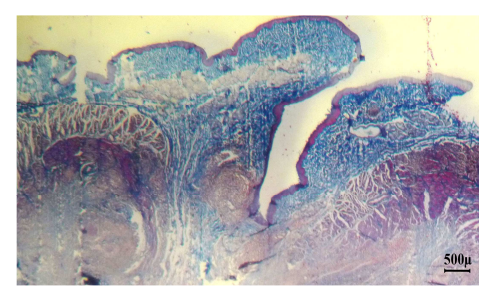

Fig. 1: Complete re-epithelialization with large amount of granulation tissue in treatment group (Masson-trichrome staining, $\mathrm{Bar}=500 \mu$ )
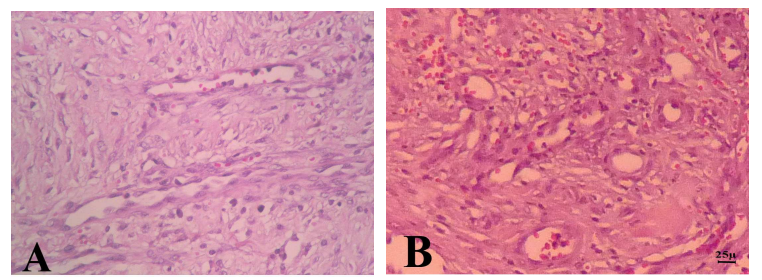

Fig. 2: Angiogenesis; (A): low vessel density in control group and (B): High vessel density in treatment group (hematoxylin-eosin staining, $\mathrm{Bar}=25 \mu$ )

The macroscopic assessment of surgical site revealed that in all dogs, esophagus was adhered to the surrounding soft tissue and there was no noticeable difference in the extent of adhesion between the two groups. No complications such as infection, dehiscence, stricture and fistula were observed in the surgical site of all dogs. In the treatment group, greater omentum was completely attached to the incision site.

Microscopic study of esophageal wounds showed that the new epithelial cells covered the surface of all esophageal wounds in both control and treatment groups and there was no significant difference in the re-epithelilization score between the groups ( $>>0.05)$ (Fig. 1). The number capillary buds in treatment group were significantly higher than the control group $(\mathrm{p}<0.05)$ (Fig. 2). The inflammatory cell in the wounds of the treatment group was significantly more than the control group. Presence of inflammatory cells especially macrophages around the wound of the treatment group were significantly more than the control group $(\mathrm{p}<0.05)$. 


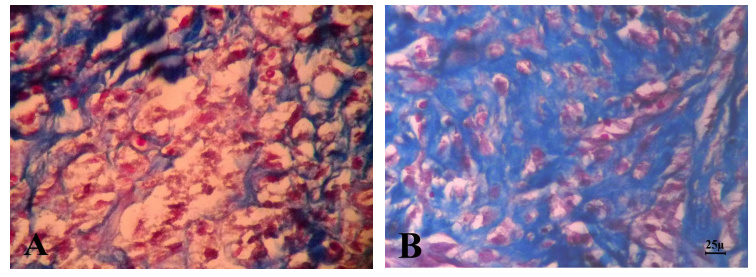

Fig. 3: Amount of collagen deposition; (A): Low collagen density in control group, (B): High collagen density in treatment group (Massontrichrome staining, Bar $=25 \mu$ )

The formation of granulation tissue in treatment group appeared to be significantly thicker and larger than control group $(p<0.05)$. The amount of collagen deposition in the treatment group was significantly more than the control group (p<0.05) (Fig. 1 and 3). Due to the injection of fresh bone marrow in the wound site of treatment group, noticeable populations of hematopoietic cells were observed in some part of the wound.

\section{DISCUSSION}

Esophageal surgery is historically associated with greater incisional dehiscence than surgery on other portion of the alimentary tract. Several factors may contribute to the high complication rate, including lack of serosa, the segmental nature of the blood supply, lack of omentum, the constant motion of swallowing and respiration and tension at the surgical site (Pavletic, 1981; Slatter, 2002). The risk of leakage from cervical anastomosis is higher than intrathoracic anastomosis (Muller et al., 1990). There are numerous recommendations to avoid postoperative complications after esophageal surgery, the important ones beinggentle handling, meticulous technique of suturing, good vascular supply and omental wrapping (Thakur et al., 2004). In recent studies, the omentum was used to cover soft tissue defects, to contribute to enhance healing, to control adhesion and to combat infection (Slatter, 2002). Recent studies have revealed that omentum, apart from being a great source of various growth factors, neurotransmitters, neurotrophic factors and inflammatory mediators, also contains omnipotent stem cells that can differentiate into a variety of cell type (Alagumuthu et al., 2006). The omentum has the highest Vescular Endothelial Growth Factor (VEGF) secretion rate as well as the highest concentration VEGF protein in comparison with other organ in rat. It has been suggested that VEGF is the major angiogenic factor produced by omentum and possibly underlies the omentum-induced angiogenesis mechanism (Zhang et al., 1997). Matoba et al. (1996) used omental implantation to repair perforated collagen ulcer in rat. Greater anti- inflammatory and angiogenic activity and accelerated collagen synthesis were seen in omental implantation group. Oloumi et al. (2006) investigated the role of free autogenous omentum in vasculogenesis during the process of bone healing. They stated that free omental graft significantly promoted angiogenesis in repaired tissue. Pap-Szekeres et al. (2003) performed transplantation and microsurgical anastomosis of free omental graft after experimental esophagectomy in dogs and declared that vital reactions, including granulation tissue and angiogenesis were present in the histological slides. There are several studies about the application of pedicle omental flap to help wound healing process in various tissues and organs, but there are some possible complications after omental transposition including; seroma formation, herniation through the omental exit hole, hemorrhage and flap necrosis (Slatter, 2002). Also in order to transpose ometal pedicle, a major laparotomy must be done (Saifzade et al., 2007). In our study the greater omentum was transplanted to the esophagus wound without vascular anastomosis. Oloumi et al. (2006) suggested that considering the angiogenic factors present in the greater omentum, it can be used at defects with no need to direct vascular connection with the recipient bed.

On the other hand, autogenous bone marrow aspirate is a useful adjuvant to enhance soft tissue healing because it contains hematopoietic cells that differentiate into red and white blood cells, platelets and macrophages and mesenchymal cells. Mesenchymal cells are multipotent and can evolve into several cell types involved in tissue repair depending on the environment they are transferred to and include osteoblasts, chondrocytes, fibroblasts and myogenic cells. Bone marrow is also the primary source of mesenchymal cells (Roukis et al., 2009; Yamaguchi et al., 2005; Chong et al., 2007; Muschler et al., 1997). Harvest of autogenous bone marrow aspirate can be performed rapidly, is simple to perform, easily reproduced andis associated with low financial cost (Roukis et al., 2009; Schweinberger and Roukis, 2007). Although other reported materials such as growth factors and cultured cells must also significantly are more effective to improve of wound healing (Oloumi et al., 2008; Badiavas and Falanga, 2003), from a practical standpoint, the use of bone marrow is more attractive because we can use the patient's own fresh cells with routine aspiration technique, allowing minimal systemic side effects (Ichioka et al., 2005).

In a clinical study, fresh bone marrow after aspiration from iliac crest, was applied directly on the chronic wound surface and injected it into the wound edges, in human. It has been suggested that all patients showed clinical improvement in their wounds within 
days following administration of bone marrow aspirate (Badiavas and Falanga, 2003); also the autogenous bone marrow aspirated from tibia plateau was used to treatment of experimental burn in rabbit skin, topically. The results demonstrated that fresh bone marrow enhanced burn wound healing (Oloumi et al., 2008). Ichioka et al. (2005) showed that bone marrowimpregnated collagen matrix can promote the wound repair process through augmentation of angiogenesis. Karaoglu et al. (2009) evaluated effect of bone marrow or periosteum on tendon-to-bone tunnel healing in a rabbit model. The results of his study showed that both periosteal graft and fresh bone marrow had benefit effect on tendon healing. They suggested that a combination of wrapping periosteum and injecting bone marrow to the tendon graft would have a synergistic effect. In another study periosteal graft has a possetive effect in healing of articular cartilage (Sharifi et al., 2006b)

The most prevalent grafts are autografts, allograft, xenografts and synthetic substances. Because of many questions about the immunologic problems of the use of allograft and xenografts (Sadi et al., 2010) and also because of easy availability of omentum and bone marrow autogenously, in the current study, autografts were applied.

In this study esophageal wound healing were evaluated histopathologically in three parts of a wound: Inflammatory exudate, Granulation tissue formation and proliferation of connective tissue (Azarabad et al., 2006).

In regard to the beneficial effects of both fresh bone marrow and free omental flap to promote wound healing and presence of several risk factors responsible for delaying in wound healing of cervical esophagus incision, the current study was designed to evaluate the combination of bone marrow and omenat free graft to improve cervical esophageal wounds repair.

According to the results of present study, simultaneous application of autogenous fresh bone marrow and free omental graft improved esophageal wound healing by noticeable angiogenesis, early proliferation of inflammatory cells and fibroblasts and acceleration in granulation tissue formation.

\section{CONCLUSION}

The current study presented the simple and practical method, which is immediately applicable without any processing procedure and major side effects to improve wound healing in esophagus. To approve this hypothesis long-term investigation should be performed.

\section{ACKNOWLEDGMENT}

This study was supported financially by the Research Council of Veterinary College, Kerman
Shahid Bahonar University, for which the authors are most grateful.

\section{REFRENCES}

Alagumuthu, M., B.B. Das, S.P. Pattanayak and M. Rasananda, 2006. The omentum: A unique organ of exceptional versatility. Indian J. Surg., 68: 136-141. http://www.bioline.org.br/pdf?is06039

Azarabad, H., I. Nowrouzian, E. Soleymani, G. Vakilgilani and S.M. Seyedjavadi, 2006. Wound healing process of uncomplicated "rusterholz" ulcer, following treatment by wooden block and hoofgel® in bovine hoof: Histopathological aspects. Am. J. Anim. Vet. Sci., 1: 27-30. DOI: 10.3844/.2006.27.30

Badiavas, E.V. and V. Falanga, 2003. Treatment of chronic wounds with bone marrow-derived cells. Arch. Dermatol., 139: 510-516. PMID: 12707099

Bhargava, J.S., A. Makker, K. Bhargava, A.V. Shaunik and A. Sharda et al., 1997. Pedicled omental transfer for ischemic limbs--a 5-year experience. J. Indian Med. Assoc., 95: 100-102. PMID: 9357269

Chong, AK., A.D. Ang, J.C. Goh, J.H. Hui and A.Y. Lim et al., 2007. Bone marrow derived mesenchymal stem cells influence early tendonhealing in a rabbit Achilles tendon model. J. Bone Joint Surg., 89: 74-81. PMID: 17200313

Ichioka, S., S. Kouraba, N. Sekiya, N. Ohura and T. Nakatsuka, 2005. Bone marrow-impregnated collagen matrix for wound healing: Experimental evaluation in a microcirculatory model of angiogenesis and clinical experience. Br. J. Plast. Surg., 58: 1124-1130. PMID: 16043157

Ismail, Z.B., A. Al-Majali and K. Al-Qudah, 2007. Clinical and surgical findings and outcome following rumenotomy in adult dairy cattle affected with recurrent rumen tympany associated with non-metallic foreign bodies. Am. J. Anim. Vet. Sci., 2: 66-71. DOI: 10.3844/.2007.66.71

Karaoglu, S., C. Celik and P. Korkusuz, 2009. The effects of bone marrow or periosteum on tendon-tobone tunnel healing in a rabbit model. Knee Surg. Sports Traumatol. Arthrosc., 17: 170-178. DOI: 10.1007/s00167-008-0646-3

Kyles, A.E., 2003. Esophagus. In: Textbook of Small Animal Surgery, Slatter, D. (Ed.). Sunders, Philadelphia, USA., ISBN: 0721686079, pp: 573-592.

Losken, A., G.W. Carison, J.H. Culbertson, C. Scott Hultman and A.V. Kumar et al., 2002. Omental free flap reconstruction in complex head and neck deformities. Head Neck, 24: 326-331. PMID: 11933173 
Matoba, Y., H. Katayama and H. Ohami, 1996. Evaluation of omental implantation for perforated gastric ulcer therapy: Finding in a rat model. J. Gastroenterol., 31: 777-784. PMID: 9027639

Moon, Y.L., S.H. Jo, C.H. Song, G. Park and H.J. Lee et al., 2008. Autologous bone marrow plasma injection after arthroscopic debridement for elbow tendinosis. Ann. Acad. Med. Singapore, 37: 559-563. PMID: 18695767

Muller, J.M., H. Erasmi, M. Stelzner, U. Zieren and H. Pichlmaier, 1990. Surgical therapy of oesophageal carcinoma. Br. J. Surg., 77: 845-857. PMID: 2203505

Muschler, G.F., C. Boehm and K. Easley, 1997. Aspiration to obtain osteoblast progenitor cells from human bone marrow: The influence of aspiration volume. J. Bone Joint Surg., 79: 1699-1709. PMID: 9384430

Nakanishi, R., T. Shirakusa and T. Takachi, 1994. Omentopexy for tracheal autograft. Ann. Thorac. Surg., 57: 841-845. PMID: 7513148

Oloumi, M.M., A. Derakhshanfar, M.M. Molaei and M. Tayyebi, 2006. The angiogenic potential of autogenous free omental graft in experimental tibial defects in rabbits: Short-term preliminary histopathological study. J. Exp. Anim. Sci., 43: 179-187. DOI: 10.1016/j.jeas.2006.02.002

Oloumi, M.M., M.M. Derakhshanfar, H. Shemali and M. Shavalian, 2008. The role of autogenous bone marrow in the healing of experimental burn wound healing in rabbits. Iran. J. Vet. Surg., 3: 47-55. http://www.ivsa.ir/pdf/Vol3No2\%202008/5.pdf

Pap-Szekeres, J., G. Cserni, I. Furka, M. Svebis and T. Cserni et al., 2003. Transplantation and microsurgical anastomosis of free omental grafts: Experimental animal model of a new operative technique in dogs. Microsurgery, 23: 414-418. PMID: 14557993

Pap-Szekeres, J., G. Cserni, I. Furka, M. Svebis and T. Cserni et al., 2005. A new concept for esophageal resection--prevascularization: An experimental study. Dis. Esoph., 18: 274-280. PMID: 16128786

Pavletic, M.M., 1981. Reconstructive esophageal surgery in the dog: A literature review and case report. J. Am. Anim. Hosp. Assoc., 17: 435-444.

Roukis, T.S., C.F. Hyer, T.M. Do, G.C. Berlet and T.H. Lee, 2009. Complications associated with autogenous bone marrow aspirate harvest from the lower extremity: An observational cohort study. J. Foot Ankle Surg., 48: 668-671. PMID: 19857823

Sadi, F., A. Veshkini, D. Sharifi and M.N. Masouleh, 2010. Ultrasonography and radiography evaluation of the cartilage graft in repair of experimentally induced radial bone defect in rabbit. Am. J. Anim. Vet. Sci., 5: 40-44. DOI: 10.3844/.2010.40.44
Saifzade, S., G. Rezazadeh, B.D. Naghadeh, B. Pourreza and S. Kazemi, 2007. Effect of autologus omental free graft on biomechanical properties of fracture healing in dog. Iran J. Vet. Surg., 2: 17-24. http://www.ivsa.ir/pdf/vol2\%20no\%204/201.pdf

Sharifi, D., A. Razaei, D. Savadkouhi, R. Sadkhanloo and M. Rezaeyan, 2006a. Gross and histomorphological studies of femoral head resurfacing in dog. Am. J. Anim. Vet. Sci., 1: 1-4. DOI: $10.3844 / .2006 .1 .4$

Sharifi, D., P. Yunessi, F. Sasani and S. Mohitmafi, 2006b. The effects of transcutaneous electrical stimulation on the healing of radial fracture in rabbit. Am. J. Anim. Vet. Sci., 1: 31-34. DOI: 10.3844/.2006.31.34

Schunk, C.M., 1990. Esophagus. In: Current Techniques in Small Animal Surgery, Bojrab, M.J. (Ed.). Lea and Febiger, USA., ISBN: 10: 0812111931, pp: 201-207.

Schweinberger, M.H. and T.S. Roukis, 2007. Percutaneous autologous bone-marrow harvest from the calcaneus and proximal tibia: surgical technique. J. Foot Ankle Surg., 46: 411-414. DOI: 10.1053/j.jfas.2007.05.009

Slatter, D., 2002. Textbook of Small Animal Surgery: 2-Volume Set. 3rd Edn., Saunders, USA., ISBN: 10: 0721686079, pp: 3070.

Thakur, B., C.S. Zhang and Z.B. Tan, 2004. Omentoplasty versus no omentoplasty for esophagogastrostomy after surgery for cancer of cardia and esophagus. Indian J. Cancer, 41: 167-169. PMID: 15659870

Yamaguchi, Y., T. Kubo, T. Murakami, M. Takahashi and Y. Hakamata et al., 2005. Bone marrow cells differentiate into wound myofibroblasts and accelerate the healing of wounds with exposed bones when combined with an occlusive dressing. Br. J. Dermatol., 152: 616-622. PMID: 15840089

Zhang, M.S., Q.Y. Ji, Z. Xu, Y.C. You and Y. He et al., 1989. The effect of transposition of pedicled omentum to spinal cord ischemic segments. An animal experiment. Chin Med. J., 102: 214-218. PMID: 2503309

Zhang, Q.X., C.J. Magovern, C.A. Mack, K.T. Budenbender and W. Ko et al., 1997. Vascular endothelial growth factor is the major angiogenic factor in omentum: Mechanism of the omentum-mediated angiogenesis. J. Surg. Res., 67: 147-154. DOI: 10.1006/jsre. 1996.4983 